ORIGINAL ARTICLE

\section{Telaprevir for Retreatment of HCV Infection}

\author{
Stefan Zeuzem, M.D., Pietro Andreone, M.D., Stanislas Pol, M.D., \\ Eric Lawitz, M.D., Moises Diago, M.D., Stuart Roberts, M.D., \\ Roberto Focaccia, M.D., Zobair Younossi, M.D., Graham R. Foster, F.C.R.P., \\ Andrzej Horban, M.D., Peter Ferenci, M.D., Frederik Nevens, M.D., \\ Beat Müllhaupt, M.D., Paul Pockros, M.D., Ruben Terg, M.D., \\ Daniel Shouval, M.D., Bart van Hoek, M.D., Ola Weiland, M.D., \\ Rolf Van Heeswijk, Pharm.D., Sandra De Meyer, Ph.D., Don Luo, Ph.D., \\ Griet Boogaerts, M.Sc., Ramon Polo, Pharm.D., Gaston Picchio, Ph.D., \\ and Maria Beumont, M.D., for the REALIZE Study Team*
}

\section{BACKGROUND}

Up to $60 \%$ of patients with hepatitis C virus (HCV) genotype 1 infection do not have a sustained virologic response to therapy with peginterferon alfa plus ribavirin.

\section{METHODS}

In this randomized, phase 3 trial, we evaluated the addition of telaprevir to peginterferon alfa-2a plus ribavirin in patients with HCV genotype 1 infection who had no response or a partial response to previous therapy or who had a relapse after an initial response. A total of 663 patients were assigned to one of three groups: the T12PR48 group, which received telaprevir for 12 weeks and peginterferon plus ribavirin for a total of 48 weeks; the lead-in T12PR 48 group, which received 4 weeks of peginterferon plus ribavirin followed by 12 weeks of telaprevir and peginterferon plus ribavirin for a total of 48 weeks; and the control group (PR48), which received peginterferon plus ribavirin for 48 weeks. The primary end point was the rate of sustained virologic response, which was defined as undetectable HCV RNA 24 weeks after the last planned dose of a study drug.

\section{RESULTS}

Rates of sustained virologic response were significantly higher in the two telaprevir groups than in the control group among patients who had a previous relapse $(83 \%$ in the T12PR 48 group, $88 \%$ in the lead-in T12PR48 group, and 24\% in the PR48 group), a partial response $(59 \%, 54 \%$, and $15 \%$, respectively), and no response $(29 \%, 33 \%$, and $5 \%$, respectively) ( $\mathrm{P}<0.001$ for all comparisons). Grade 3 adverse events (mainly anemia, neutropenia, and leukopenia) were more frequent in the telaprevir groups than in the control group ( $37 \%$ vs. $22 \%$ ).

\section{CONCLUSIONS}

Telaprevir combined with peginterferon plus ribavirin significantly improved rates of sustained virologic response in patients with previously treated HCV infection, regardless of whether there was a lead-in phase. (Funded by Tibotec and Vertex Pharmaceuticals; REALIZE ClinicalTrials.gov number, NCT00703118.)
The authors' affiliations are listed in the Appendix. Address reprint requests to Dr. Zeuzem at the Department of Internal Medicine, Johann Wolfgang Goethe University Hospital, Theodor Stern Kai 7, 60590 Frankfurt, Germany, or at zeuzem@ em.uni-frankfurt.de.

*The members of the REALIZE study team are listed in the Supplementary Appendix, available at NEJM.org.

N Engl J Med 2011;364:2417-28.

Copyright (c) 2011 Massachusetts Medical Society. 
PPROXIMATELY $60 \%$ OF PATIENTS WHO are infected with hepatitis $\mathrm{C}$ virus (HCV) genotype 1 are not cured by 48 weeks of peginterferon alfa combined with ribavirin. ${ }^{1}$ Such patients fall into one of three categories: those who have no response to therapy, which is defined as a reduction of less than $2 \log _{10}$ in HCV RNA levels after 12 weeks of therapy ${ }^{2}$; those who have a partial response, which is defined as a reduction of at least $2 \log _{10}$ in a patient who has always had detectable serum HCV RNA during therapy; and those who have a relapse, which is defined as undetectable serum HCV RNA at the end of treatment but with subsequent virologic relapse.

In two recent phase 2 trials, telaprevir, an orally bioavailable inhibitor of the nonstructural 3/4A $\mathrm{HCV}$ protease, ${ }^{3}$ substantially enhanced rates of sustained virologic response when it was combined with peginterferon plus ribavirin in patients who had received previous therapy. ${ }^{4,5}$ In this randomized, double-blind, placebo-controlled, phase 3 study, we assessed the efficacy and safety of the addition of telaprevir to a regimen of peginterferon plus ribavirin in patients with chronic $\mathrm{HCV}$ genotype 1 infection who did not have a sustained virologic response to previous treatment.

\section{METHODS}

\section{PATIENTS}

From September 2008 through July 2010, we enrolled patients at study centers in 17 countries in Europe, South America, and North America, as well as in Israel, and Australia. All patients were between the ages of 18 and 70 years, had chronic HCV genotype 1 infection, did not have a sustained virologic response to one previous course of peginterferon plus ribavirin despite receiving at least $80 \%$ of the intended dose, and had well-characterized data on the previous treatment. Eligible patients had detectable HCV RNA, had undergone liver biopsy within 18 months before screening, and had an absolute neutrophil count of at least 1200 per cubic millimeter, a platelet count of at least 90,000 per cubic millimeter, and a hemoglobin level of at least $12 \mathrm{~g}$ per deciliter for women and $13 \mathrm{~g}$ per deciliter for men. Patients were excluded if they had decompensated liver disease, other causes of significant liver disease, or active cancer.

The protocol (which is available with the full text of this article at NEJM.org) was approved by the independent ethics committee at each participating study center (for a complete list, see the
Supplementary Appendix, available at NEJM.org). The study was performed in accordance with the provisions of the Declaration of Helsinki and Good Clinical Practice guidelines. All patients provided written informed consent.

\section{STUDY DESIGN}

Patients were stratified according to their baseline viral load (HCV RNA, $<800,000$ or $\geq 800,000$ IU per milliliter) and type of previous response to peginterferon plus ribavirin (no response, partial response, or relapse). No response was defined as a reduction of less than $2 \log _{10}$ in HCV RNA after 12 weeks of therapy. Partial response was defined as a reduction of $2 \log _{10}$ or more in HCV RNA after 12 weeks of therapy but with detectable HCV RNA. Relapse was defined as undetectable HCV RNA at the end of a previous course of therapy with HCV RNA positivity thereafter.

Telaprevir (Tibotec) was administered orally at a dose of $750 \mathrm{mg}$ every 8 hours; peginterferon alfa2a (Pegasys, Roche) was administered subcutaneously at a dose of $180 \mu \mathrm{g}$ per week; and ribavirin (Copegus, Roche) was administered orally at a dose of 1000 to $1200 \mathrm{mg}$ per day.

Patients were randomly assigned to one of two groups receiving telaprevir (with or without a leadin period of therapy with peginterferon alfa-2a plus ribavirin) or a control group that received placebo along with peginterferon alfa-2a plus ribavirin in a 2:2:1 ratio. Randomization was performed with the use of a centralized system according to a predefined randomization list, constructed through random permuted blocks. In the T12PR48 group, 266 patients were assigned to receive telaprevir, peginterferon, and ribavirin for 12 weeks, followed by placebo plus peginterferon and ribavirin for 4 weeks, and then peginterferon plus ribavirin alone for 32 weeks. In the lead-in T12PR48 group, 264 patients were assigned to receive placebo, peginterferon, and ribavirin for 4 weeks, followed by telaprevir plus peginterferon plus ribavirin for 12 weeks, and then peginterferon plus ribavirin alone for 32 weeks. In the PR48 (control) group, 132 patients were assigned to receive placebo, peginterferon, and ribavirin for 16 weeks, followed by peginterferon plus ribavirin for 32 weeks. In all the groups, study drugs were administered for 48 weeks.

All study investigators, patients, and the sponsors were unaware of study-group assignments until all patients had reached week 72, unless unblinding was necessary for medical reasons. Re- 
sults of HCV RNA tests up to week 24 were masked and were monitored by an independent reviewer to assess whether patients had met a predefined stopping rule. Telaprevir was stopped if HCV RNA levels were greater than 100 IU per milliliter at weeks 4,6 , and 8 after the start of telaprevir treatment; in such cases, patients were able to continue receiving peginterferon plus ribavirin. All treatment had to be discontinued if patients had less than a $2 \log _{10}$ decrease in HCV RNA at week 12 in the T12PR48 group and the control group or at week 16 in the lead-in T12PR48 group or in cases of detectable HCV RNA at week 24 or 36. Patients who discontinued telaprevir because of the stopping rule were considered to have had virologic failure.

\section{STUDY OVERSIGHT}

The first author participated in the development of the study design and protocol development with the study sponsors. The first author also wrote the first draft of the manuscript and vouches for the completeness and veracity of the data and data analyses, as well as the fidelity of the report to the trial protocol. Editorial assistance in the preparation of the manuscript was funded by Janssen Pharmaceuticals, the parent company of Tibotec. Peginterferon and ribavirin were purchased from the manufacturers. All authors reviewed and approved the final form of the manuscript and made the decision to submit it for publication.

\section{EFFICACY ASSESSMENTS}

We performed plasma HCV RNA quantification using the COBAS TaqMan assay (Roche), version 2.0, which has a lower limit of quantification of 25 IU per milliliter and a limit of detection of $10 \mathrm{IU}$ per milliliter. HCV RNA levels were measured at screening, at baseline, on day 3 , and during weeks $1,2,4,5,6,8,10,12,14,16,20,24,36$, and 48 , as well as at the time of early discontinuation, at follow-up visits 4, 12, and 24 weeks after end of treatment, and at week 72 , even in patients who discontinued early.

\section{VIROLOGIC ASSESSMENTS}

To analyze for resistant variants, HCV RNA was isolated from plasma, and the nonstructural 3/4A protease domains were amplified by reverse-transcriptase polymerase-chain-reaction assay and sequenced. Analyses were performed on baseline samples and in cases of virologic failure (i.e., in cases of viral breakthrough or cases in which pa- tients met a virologic stopping rule) or relapse. Viral breakthrough was defined as an increase of at least $1 \log _{10}$ in HCV RNA from the nadir reached during treatment or an HCV RNA level of more than $100 \mathrm{IU}$ per milliliter in patients whose viral load had previously been less than 25 IU per milliliter during treatment. Telaprevir-resistant variants included V36A/M, T54A/S, R155I/K/M/T, and A156S/T/V. ${ }^{6}$

\section{SAFETY ASSESSMENTS}

Data on all adverse events were collected throughout the treatment period and at the safety followup assessment 4 weeks after the administration of the last dose of a study drug. Serious adverse events continued to be monitored throughout the follow-up period. Laboratory assessments were performed at the same time points as efficacy assessments.

Guidance for the management and grading of rash was included according to the following criteria: grade 1 (mild, localized to one or several sites), grade 2 (moderate, with a diffuse skin eruption involving up to $50 \%$ of body surface), and grade 3 (severe, involving more than $50 \%$ of body surface or rash with the appearance of major systemic signs or symptoms). For patients with grade 1 or 2 rash, medical management was performed at the discretion of the investigator. For patients with grade 2 rash that progressed or did not improve or any grade 3 rash, telaprevir was discontinued while the patient continued to receive peginterferon plus ribavirin. The discontinuation of ribavirin (with or without peginterferon) was then suggested if the rash did not improve within 7 days after the discontinuation of telaprevir.

For the management of anemia, reductions in the ribavirin dose were made in accordance with drug labeling. Reductions in the telaprevir dose were prohibited, as was the use of erythropoietin-stimulating agents. If reductions in the ribavirin dose or discontinuation did not result in improvement in anemia, then telaprevir therapy was stopped. An independent data and safety monitoring board analyzed safety data at predefined time points during the study.

\section{PRIMARY AND SECONDARY END POINTS}

The primary end point was the proportion of patients with either a previous relapse or lack of a previous response who had a sustained virologic response (i.e., undetectable plasma HCV RNA 24 weeks after the last planned administration of a 
study drug). Secondary end points included the effect of lead-in treatment with peginterferon plus ribavirin on sustained virologic response, the proportion of patients who had undetectable HCV RNA at 4 and 8 weeks, the proportion of patients who had a relapse, and the change from baseline in $\log _{10}$ HCV RNA.

\section{STATISTICAL ANALYSIS}

All analyses were performed on the intention-totreat principle in all patients who underwent randomization and received at least one dose of a study drug. The analysis of the primary end point was based on a logistic-regression model that included study group, the type of previous response (no response, partial response, or relapse), and their interaction as factors and the baseline viral RNA as a covariate. We used the Hochberg procedure to adjust for multiple comparisons. The primary objective was to show superior rates of sustained virologic response in each of the two telaprevir study groups, as compared with the control group, separately in patients who had a previous relapse or did not have a virologic response (either no response or a partial response) to therapy.

The estimated study sample size of 650 patients was calculated on the basis of the primary objective to provide a power of $90 \%$. The calculation was performed with the use of a two-sided continuity-corrected chi-square test. A P value of 0.05 was considered to indicate statistical significance. On the basis of the results of the Protease Inhibition for Viral Evaluation 3 (PROVE3) trial (ClinicalTrials.gov number, NCT00420784), ${ }^{4}$ it was estimated that virologic response rates with telaprevir would be $55 \%$, as compared with $29 \%$ in the control group, in patients who had a relapse and $30 \%$ versus $8 \%$ in patients who had no response or a partial response to previous therapy.

One of the secondary end points, the change from baseline in $\log _{10}$ HCV RNA levels, was displayed over time descriptively and explored with the use of a longitudinal statistical model. Subgroup analyses of sustained virologic response according to the stage of liver fibrosis and the baseline viral load were conducted to determine the robustness of the primary analysis.

\section{RESULTS}

\section{PATIENTS}

Of 833 patients who were screened, 663 underwent randomization, and 662 received at least one dose of a study drug (intention-to-treat population) (Fig. 1). The baseline characteristics of the patients and their disease level were similar in the three study groups (Table 1). A total of $26 \%$ of the patients had cirrhosis. Overall, $53 \%$ of the patients had a previous relapse, $19 \%$ had a partial response, and $28 \%$ had no response. Baseline telaprevir-resistant variants were uncommon (in 12 patients with T54S, 4 with R155K, and 2 with V36M).

\section{EFFICACY}

Changes in $\log _{10}$ HCV RNA levels during treatment are shown in Figure 2. The proportion of patients who had a sustained virologic response was significantly higher in the two telaprevir groups than in the control group for patients who had a previous relapse $83 \%$ in the T12PR48 group, $88 \%$ in the lead-in T12PR48 group, and $24 \%$ in the control group) and for those who did not have a previous virologic response $(41 \%, 41 \%$, and $9 \%$, respectively), including those who had a partial response (59\%, 54\%, and 15\%, respectively) and those who had no response $(29 \%, 33 \%$, and $5 \%$, respectively) ( $\mathrm{P}<0.001$ for all comparisons) (Table 2). Rates of sustained virologic response were similar in the T12PR48 group and the lead-in T12PR48 group for patients who had a relapse or no response or a partial response to previous therapy. The rate of sustained virologic response was also significantly higher for the pooled subgroup of patients who had either a relapse or a partial response in the telaprevir groups than in the control group ( $78 \%$ vs. $21 \%, \mathrm{P}<0.001)$.

Overall, the rates of sustained virologic response were 64\% in the T12PR48 group, 66\% in the lead-in T12PR48 group, and 17\% in the control group. The differences in the rates of sustained virologic response were 47 percentage points between the T12PR48 group and the control group ( $95 \%$ confidence interval $[\mathrm{CI}], 37$ to $57 ; \mathrm{P}<0.001$ ) and 50 percentage points between lead-in T12PR48 group and the control group (95\% CI, 40 to 60; $\mathrm{P}<0.001$ ).

Subgroup analyses according to the stage of liver fibrosis (Table 2) or baseline viral load (Table 1 in the Supplementary Appendix) showed higher rates of sustained virologic response among patients receiving telaprevir than among those receiving peginterferon plus ribavirin alone.

Relapse rates were lower in the two telaprevir groups than in the control group among patients who had a previous relapse or no response or a partial response to previous therapy (Table 2). 
Among patients who had a relapse, virologic failure during treatment was observed in 3 patients (1\%) in the two telaprevir groups and in 18 patients (26\%) in the control group. Among patients who had a previous partial response to therapy, virologic failure was observed in 9 patients $(18 \%)$ in the T12PR48 group, 9 (19\%) in the lead-in T12PR48 group, and 19 (70\%) in the control group. For patients who had no previous response to therapy, virologic failure was observed in 41 patients $(57 \%)$ in the T12PR48 group, 35 (47\%) in the lead-in
T12PR48 group, and 31 (84\%) in the control group during the overall treatment phase (Table 2).

Among all virologic failures and relapses, 73\% were associated with the emergence of variants with a reduced sensitivity to telaprevir. There were no differences in the number or type of emerging viral variants between the two telaprevir groups. Resistant variants were consistent with those that have been reported previously. ${ }^{6}$ In 60 of 104 patients (58\%) with variants that had a reduced sensitivity to telaprevir (primarily in those with

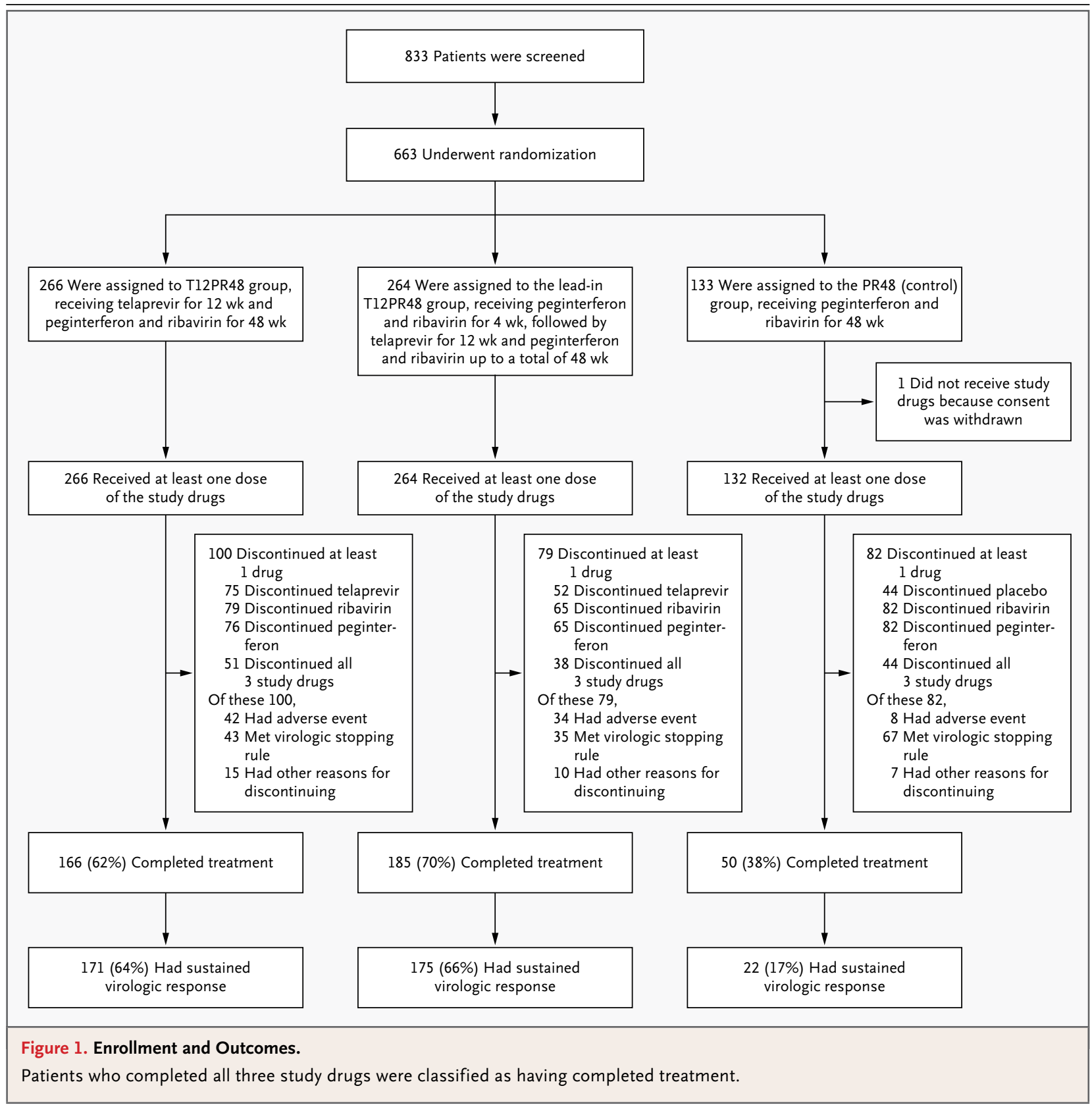

N ENGLJ MED 364;25 NEJM.ORG JUNE 23, 2011

The New England Journal of Medicine

Downloaded from nejm.org at UNIVERSITEIT GENT on June 30, 2011. For personal use only. No other uses without permission. 


\begin{tabular}{|c|c|c|c|}
\hline Characteristic & $\begin{array}{l}\text { T12PR48 } \\
\text { ( } N=266)\end{array}$ & $\begin{array}{l}\text { Lead-in T12PR48 } \\
(\mathrm{N}=\mathbf{2 6 4})\end{array}$ & $\begin{array}{l}\text { PR48 (Control) } \\
\quad(\mathrm{N}=132)\end{array}$ \\
\hline Age in years - mean (range) & $51(23-69)$ & $51(24-70)$ & $50(21-69)$ \\
\hline Body-mass index & $28 \pm 5.0$ & $27 \pm 4.8$ & $27 \pm 4.6$ \\
\hline Male sex — no. (\%) & $183(69)$ & $189(72)$ & $88(67)$ \\
\hline \multicolumn{4}{|l|}{ Race or ethnic group - no. $(\%) \ddagger$} \\
\hline White & $246(92)$ & $252(95)$ & $117(89)$ \\
\hline Black & $11(4)$ & $8(3)$ & $11(8)$ \\
\hline Asian or other & $9(3)$ & $4(2)$ & $4(3)$ \\
\hline Hispanic & $25(9)$ & $27(10)$ & $20(15)$ \\
\hline Alanine aminotransferase - IU/liter & $88 \pm 63$ & $80 \pm 56$ & $82 \pm 58$ \\
\hline Total bilirubin $-\mu \mathrm{mol} / \mathrm{liter}$ & $12 \pm 6$ & $12 \pm 5$ & $12 \pm 5$ \\
\hline Serum albumin $-\mathrm{g} /$ liter & $41 \pm 3$ & $42 \pm 3$ & $42 \pm 3$ \\
\hline Platelet count - per $\mathrm{mm}^{3}$ & $217,000 \pm 67,000$ & $219,000 \pm 74,000$ & $221,000 \pm 71,000$ \\
\hline \multicolumn{4}{|l|}{ HCV genotype 1 subtype - no. (\%) $\int$} \\
\hline la & $118(44)$ & $121(46)$ & $59(45)$ \\
\hline $1 b$ & $121(45)$ & $115(44)$ & $59(45)$ \\
\hline lc & 0 & 0 & $1(1)$ \\
\hline Unknown & $27(10)$ & $28(11)$ & $13(10)$ \\
\hline HCV RNA $\log _{10}-I U / m \mid q \|$ & $6.6 \pm 0.03$ & $6.6 \pm 0.04$ & $6.6 \pm 0.05$ \\
\hline HCV RNA $\geq 800,000 \mathrm{lU} / \mathrm{ml}$ - no. (\%) 9 & $238(89)$ & $234(89)$ & $114(86)$ \\
\hline \multicolumn{4}{|l|}{ Stage of fibrosis or cirrhosis - no. (\%)** } \\
\hline No or minimal fibrosis & $51(19)$ & $68(26)$ & $35(27)$ \\
\hline Portal fibrosis & $83(31)$ & $71(27)$ & $38(29)$ \\
\hline Bridging fibrosis & $60(23)$ & $58(22)$ & $29(22)$ \\
\hline Cirrhosis & $72(27)$ & $67(25)$ & $30(23)$ \\
\hline \multicolumn{4}{|l|}{ Previous type of response - no. (\%) } \\
\hline No response & $72(27)$ & $75(28)$ & $37(28)$ \\
\hline Partial response & $49(18)$ & $48(18)$ & $27(20)$ \\
\hline Relapse & $145(55)$ & $141(53)$ & $68(52)$ \\
\hline \multicolumn{4}{|c|}{$\begin{array}{l}\text { Plus-minus values are means } \pm \text { SD unless otherwise indicated. There were no significant differences among the study } \\
\text { groups for any characteristic. Percentages may not total } 100 \text { because of rounding. } \\
\text { Body-mass index is the weight in kilograms divided by the square of the height in meters. } \\
\text { Race or ethnic group was self-reported. Patients of any race could also identify themselves as Hispanic. } \\
\text { The HCV genotype and subtype were determined with the use of the Trugene HCV genotyping assay (Siemens) except } \\
\text { for one patient in the lead-in Tl2PR48 group, in whom the subtype was determined with the use of an NS3 assay. } \\
\text { HCV RNA levels were measured with the use of the COBAS TaqMan HCV assay, version } 2.0 \text { (Roche). } \\
\text { Log }_{10} \text { values for HCV RNA are means } \pm \text { SE. } \\
\text { Patients were grouped into four categories of fibrosis, according to the following Metavir and Ishak fibrosis scores: } \\
\text { minimal or no fibrosis (Metavir, F0-Fl; Ishak, 0-2), portal fibrosis (Metavir, F2; Ishak, 3), bridging fibrosis (Metavir, } \\
\text { F3; Ishak, 4), and cirrhosis (Metavir, F4; Ishak, 5-6). }\end{array}$} \\
\hline
\end{tabular}

virologic failure), resistant variants were no longer detected by population sequencing at the end of the study (median follow-up, 46.4 weeks).

\section{ADVERSE EVENTS}

The most frequently reported adverse events (occurring in more than $25 \%$ of patients) in the two tela- previr groups were fatigue, pruritus, rash, nausea, influenza-like illness, anemia, and diarrhea (Table 2 in the Supplementary Appendix). Grade 3 adverse events (mainly anemia, neutropenia, and leukopenia) were reported more frequently in the two telaprevir groups than in the control group during the overall study period (with a rate of $37 \%$ 


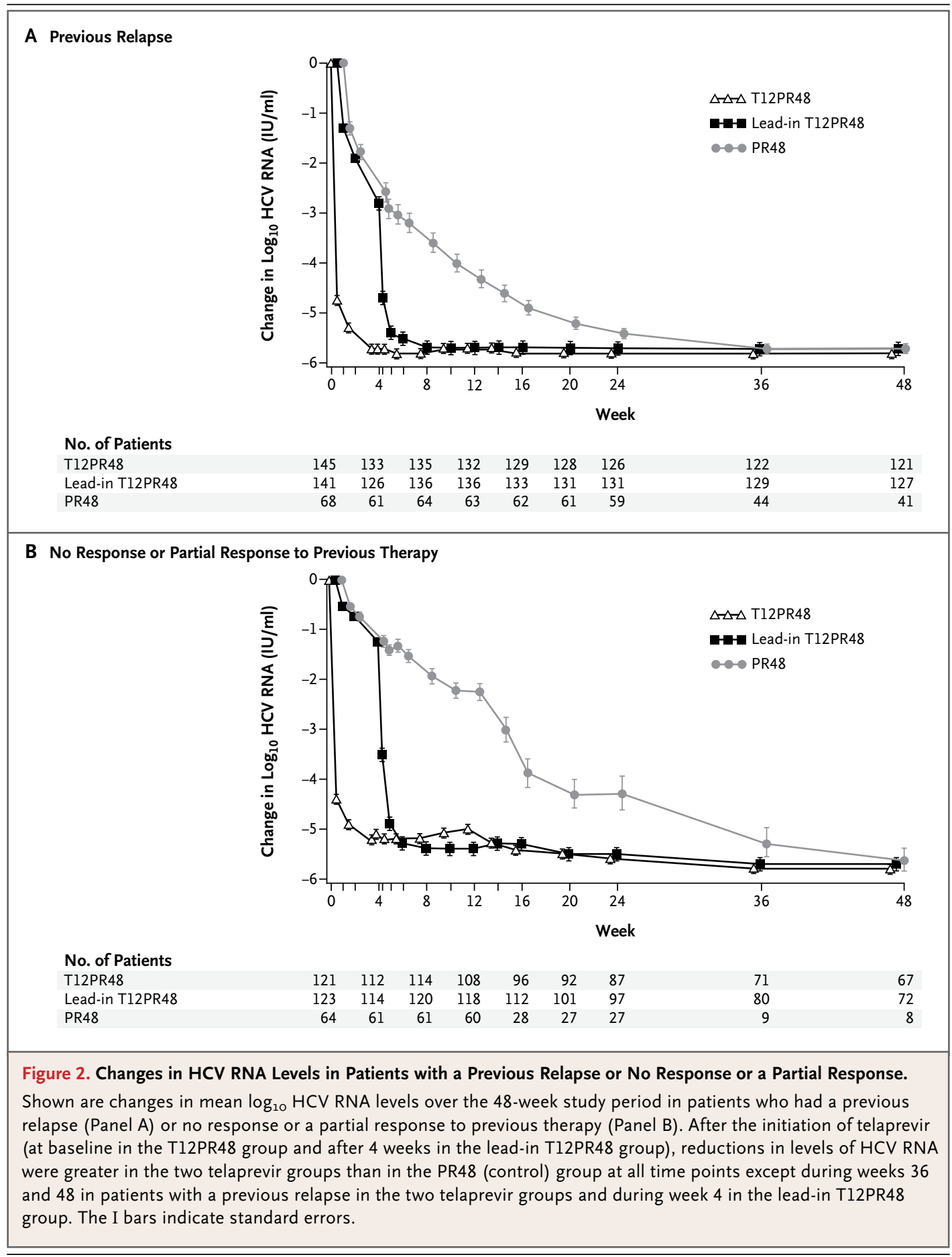

vs. $22 \%$ ). Serious adverse events and adverse events leading to permanent discontinuation of a study drug (mainly anemia in both cases) were also more frequent in the two telaprevir groups than in the control group. In the two telaprevir groups, the rate of serious adverse events was $12 \%$ and the rate of adverse events leading to permanent dis- continuation of a study drug was $13 \%$, as compared with rates of 5\% and 3\%, respectively, in the control group (Table 3).

In the two telaprevir groups, the rate of grade 3 rash was 3\%, and the rate of grade 3 pruritus was $1 \%$, as compared with no patients in the control group. Rash as an adverse event of special interest 
(i.e., a grade 3 skin event, any skin event resulting in permanent discontinuation of any or all study drugs, or any skin event defined as a serious adverse event) occurred in 5\% of patients in the two telaprevir groups, as compared with no patients in the control group. In the two telaprevir groups, $4 \%$ of patients discontinued telaprevir and $1 \%$ of patients discontinued all drugs because of rash. No patients discontinued treatment because of rash in the control group.

\section{I SCUSSION}

Telaprevir in combination with peginterferon alfa2a plus ribavirin significantly improved the rates of sustained virologic response for patients who had received previous therapy for HCV infection. As in previous trials, ${ }^{4,5,7}$ the rates of sustained virologic response differed among patients who had a previous relapse, those who had no response to previous therapy, and those who had a partial response. In another study, ${ }^{8}$ investigators found improved rates of sustained virologic response for patients who had a previous relapse or partial response after the addition of boceprevir, another HCV serine protease inhibitor, to peginterferon alfa-2b plus ribavirin. Unlike the study of boceprevir, our study also included patients who had no response to previous therapy (i.e., a reduction of $<2 \log _{10}$ in HCV RNA at week 12). In these patients, telaprevir combined with peginterferon plus ribavirin increased the rate of sustained vi-

\begin{tabular}{|c|c|c|c|}
\hline Subgroup and End Point & T12PR48 & $\begin{array}{l}\text { Lead-in T12PR48 } \\
\text { no./total no. (\%) }\end{array}$ & PR48 (Control) \\
\hline \multicolumn{4}{|l|}{ Previous relapse } \\
\hline \multicolumn{4}{|l|}{ Undetectable viral load } \\
\hline At 4 wk & $101 / 145(70)$ & $4 / 141(3)$ & $2 / 68(3)$ \\
\hline At $8 w k$ & $135 / 145(93)$ & $126 / 141(89)$ & $7 / 68(10)$ \\
\hline \multicolumn{4}{|l|}{ Sustained virologic response } \\
\hline All patients & $121 / 145(83) \dagger$ & $124 / 141(88) \dagger$ & $16 / 68(24)$ \\
\hline \multicolumn{4}{|l|}{ Patients with undetectable viral load } \\
\hline At 4 wk & $91 / 101(90)$ & $4 / 4(100)$ & $2 / 2(100)$ \\
\hline At $8 w k$ & $121 / 135(90)$ & $116 / 126(92)$ & $7 / 7(100)$ \\
\hline Patients with bridging fibrosis or cirrhosist & $54 / 64(84)$ & $47 / 55(85)$ & $4 / 30(13)$ \\
\hline Relapse at $72 \mathrm{wk} \mathbb{J}$ & $10 / 135(7)$ & $9 / 138(7)$ & $30 / 46(65)$ \\
\hline Virologic failure & $2 / 145(1)$ & $1 / 141(1)$ & $18 / 68(26)$ \\
\hline \multicolumn{4}{|l|}{$\begin{array}{l}\text { No response or partial response to previous } \\
\text { therapy }\end{array}$} \\
\hline Sustained virologic response & $50 / 121(41) \dagger$ & $51 / 123(41) \dagger$ & $6 / 64(9)$ \\
\hline \multicolumn{4}{|l|}{ Previous partial response } \\
\hline \multicolumn{4}{|l|}{ Undetectable viral load } \\
\hline At 4 wk & $32 / 49(65)$ & 0 & 0 \\
\hline At $8 w k$ & $40 / 49(82)$ & $31 / 48(65)$ & 0 \\
\hline \multicolumn{4}{|l|}{ Sustained virologic response } \\
\hline All patients & $29 / 49(59) \dagger$ & $26 / 48(54) \dagger$ & $4 / 27(15)$ \\
\hline \multicolumn{4}{|l|}{ Patients with undetectable viral load } \\
\hline At 4 wk & $23 / 32(72)$ & NA & NA \\
\hline At $8 w k$ & $27 / 40(68)$ & $18 / 31(58)$ & NA \\
\hline Patients with bridging fibrosis or cirrhosist & $11 / 25(44)$ & $10 / 25(40)$ & $1 / 10(10)$ \\
\hline Relapse at $72 \mathrm{wkJ}$ & $8 / 39(21)$ & $9 / 36(25)$ & 0 \\
\hline Virologic failure & $9 / 49(18)$ & $9 / 48(19)$ & $19 / 27(70)$ \\
\hline
\end{tabular}




\begin{tabular}{|c|c|c|c|}
\hline \multicolumn{4}{|l|}{ Table 2. (Continued.) } \\
\hline \multirow[t]{2}{*}{ Subgroup and End Point } & T12PR48 & Lead-in T12PR48 & PR48 (Control) \\
\hline & & no./total no. (\%) & \\
\hline \multicolumn{4}{|l|}{ No previous response } \\
\hline \multicolumn{4}{|l|}{ Undetectable viral load } \\
\hline At 4 wk & $19 / 72(26)$ & 0 & $1 / 37(3)$ \\
\hline At $8 w k$ & $34 / 72$ (47) & $31 / 75(41)$ & $1 / 37(3)$ \\
\hline \multicolumn{4}{|l|}{ Sustained virologic response } \\
\hline All patients & $21 / 72(29) \dagger$ & $25 / 75(33) \dagger$ & $2 / 37(5)$ \\
\hline \multicolumn{4}{|l|}{ Patients with undetectable viral load } \\
\hline At 4 wk & $10 / 19(53)$ & NA & $1 / 1(100)$ \\
\hline At 8 wk & $20 / 34(59)$ & $21 / 31(68)$ & $1 / 1(100)$ \\
\hline Patients with bridging fibrosis or cirrhosis & $12 / 43(28)$ & $10 / 45(22)$ & $1 / 19(5)$ \\
\hline Relapse at $72 \mathrm{wk} \mathbb{J}$ & $8 / 30(27)$ & $9 / 36(25)$ & $3 / 5(60)$ \\
\hline Virologic failure & $41 / 72(57)$ & $35 / 75(47)$ & $31 / 37(84)$ \\
\hline \multicolumn{4}{|c|}{$\begin{array}{l}\text { Data are for all patients who received at least one dose of a study drug. NA denotes not applicable because there were } \\
\text { no patients in this group with undetectable HCV RNA at the corresponding earlier time point (at } 4 \text { or } 8 \text { weeks). } \\
\text { P<0.001 for the comparison with the control group by means of logistic-regression analysis. } \\
\text { Statistical models showed that there was no significant association between the baseline viral load and sustained viro- } \\
\text { logic response. The stage of liver fibrosis was shown to have a significant effect on outcome, particularly among pa- } \\
\text { tients who had no response or a partial response to previous therapy. } \\
\text { Values are for patients who had undetectable HCV RNA at the end of the assigned treatment. } \\
\text { A determination of virologic failure was based on either viral breakthrough or discontinuation of a study drug because } \\
\text { of meeting a virologic stopping rule. }\end{array}$} \\
\hline
\end{tabular}

rologic response from 5\% to a range of 29 to $33 \%$. Even though this therapy increased the rate of sustained virologic response by nearly six times, further improvements are warranted.

Among patients who have had no response or a partial response to previous therapy, those with a high baseline viral load and advanced liver fibrosis have disease that is particularly difficult to cure. ${ }^{9,10}$ In our study, more than $85 \%$ of patients had a high baseline viral load (i.e., above 800,000 IU per milliliter), $26 \%$ had liver cirrhosis, and $22 \%$ had bridging fibrosis. No specific safety and tolerability issues were associated with the use of telaprevir in patients with an advanced stage of liver fibrosis, and in such patients the rates of sustained virologic response were higher in the telaprevir groups than in the control group. Although the baseline viral load was not a significant prognostic factor for rates of sustained virologic response among patients receiving telaprevir, the presence of advanced fibrosis appeared to have a negative effect on the rates of sustained virologic response among patients who had no response or a partial response to previous thera- py, although there was no such effect on those who had a previous relapse.

We investigated the role of a 4-week lead-in phase with peginterferon alfa-2a plus ribavirin before the addition of telaprevir. In a smaller study of boceprevir, it seemed that lowering of the viral load with pretreatment with peginterferon alfa- $2 b$ plus ribavirin may have reduced the emergence of protease-resistant variants, lowered the rate of virologic breakthrough during treatment, and improved the rate of sustained virologic response. ${ }^{11}$ However, we did not observe any significant differences between the concurrent and delayed initiation of telaprevir with peginterferon plus ribavirin in the rates of sustained virologic response.

Overall, virologic failure rates during therapy were lower in patients who had a previous relapse or a partial response than in patients who had no response to previous therapy. Selection and persistence of drug-resistant variants is a common concern in the use of direct-acting antiviral agents. ${ }^{12}$ As described previously ${ }^{4,13,14}$ and implemented in the present study, strict application of stopping rules may help to avoid the selection and long-term 
persistence of HCV variants with telaprevir resistance. Furthermore, in $58 \%$ of patients who had variants with reduced sensitivity to telaprevir, such variants were no longer detectable by population sequencing at the end of the study.

The safety profile of telaprevir with peginterferon plus ribavirin was consistent across all phase 2 and phase 3 trials, which included more than 2800 patients. ${ }^{4,5,13-17}$ The addition of telaprevir to peginterferon plus ribavirin was particularly associated with increased rates of fatigue, gastrointestinal side effects, pruritus, and rash ${ }^{4,13,14}$ and was associated with an increase of 8 to 12 percentage points in discontinuation rates, as compared with placebo. Among patients receiving tela- previr, $4 \%$ discontinued telaprevir and $1 \%$ discontinued all study drugs because of rash. Although combining telaprevir with peginterferon plus ribavirin also increased the anemia rate, the rate of discontinuation of all study drugs because of anemia was low (1\%), despite the prohibition of the use of erythropoietin-stimulating agents. A post hoc analysis showed that reductions in the dose of ribavirin in order to manage anemia were not associated with a decrease in rates of sustained virologic response (data not reported).

The presence of interleukin-28B genetic polymorphisms have been shown to be a key predictor of the response to peginterferon plus ribavirin in patients with HCV infection. ${ }^{18,19}$ A potential limi-

\begin{tabular}{|c|c|c|c|}
\hline \multirow[t]{2}{*}{ Variable } & \multirow[t]{2}{*}{$\begin{array}{l}\text { T12PR48 } \\
(N=266)\end{array}$} & $\begin{array}{l}\text { Lead-in T12PR48 } \\
\quad(\mathrm{N}=264)\end{array}$ & \multirow[t]{2}{*}{$\begin{array}{l}\text { PR48 (Control) } \\
\quad(\mathrm{N}=132)\end{array}$} \\
\hline & & no. (\%) & \\
\hline \multicolumn{4}{|l|}{ Reason for discontinuation' } \\
\hline Any adverse event & $39(15)$ & $29(11)$ & $4(3)$ \\
\hline Rasht & $12(5)$ & $10(4)$ & 0 \\
\hline Anemiał & $6(2)$ & $9(3)$ & 0 \\
\hline Pruritus & $1(<1)$ & $3(1)$ & 0 \\
\hline \multicolumn{4}{|l|}{ Serious adverse event } \\
\hline Any & $33(12)$ & $32(12)$ & $7(5)$ \\
\hline \multicolumn{4}{|l|}{ Blood or lymphatic system disorder } \\
\hline Any & $8(3)$ & $7(3)$ & $1(1)$ \\
\hline Anemia & $6(2)$ & $7(3)$ & $1(1)$ \\
\hline Infection & $6(2)$ & $9(3)$ & $2(2)$ \\
\hline Bronchitis & $2(1)$ & 0 & 0 \\
\hline Sepsis & 0 & $2(1)$ & 0 \\
\hline \multicolumn{4}{|l|}{ Skin or subcutaneous-tissue disorder } \\
\hline Any & $3(1)$ & $5(2)$ & 0 \\
\hline Toxic skin eruption & 0 & $2(1)$ & 0 \\
\hline \multicolumn{4}{|l|}{ Cardiac disorder } \\
\hline Any & $5(2)$ & $2(1)$ & $1(1)$ \\
\hline Acute myocardial infarction & $3(1)$ & 0 & 0 \\
\hline Atrial fibrillation & 0 & $2(1)$ & $1(1)$ \\
\hline Gastrointestinal disorder & $4(2)$ & $3(1)$ & $2(2)$ \\
\hline \multicolumn{4}{|c|}{$\begin{array}{l}\text { Neoplasm (benign, malignant, or unspecified, } \\
\text { including cysts and polyps) }\end{array}$} \\
\hline Any & $3(1)$ & $4(2)$ & 0 \\
\hline Gastric cancer & 0 & $2(1)$ & 0 \\
\hline Hepatic malignant neoplasm & $2(1)$ & 0 & 0 \\
\hline
\end{tabular}




\begin{tabular}{|c|c|c|c|}
\hline \multicolumn{4}{|l|}{ Table 3. (Continued.) } \\
\hline \multirow[t]{2}{*}{ Variable } & $\begin{array}{l}\text { T12PR48 } \\
(\mathrm{N}=266)\end{array}$ & $\begin{array}{l}\text { Lead-in T12PR48 } \\
\quad(N=264)\end{array}$ & $\begin{array}{l}\text { PR48 (Control) } \\
\text { (N=132) }\end{array}$ \\
\hline & \multicolumn{3}{|c|}{ no. (\%) } \\
\hline Injury, poisoning, or procedural complication & $1(<1)$ & $3(1)$ & 0 \\
\hline Nervous system disorder & $1(<1)$ & $3(1)$ & $2(2)$ \\
\hline General disorder or injection-site condition & $1(<1)$ & $2(1)$ & 0 \\
\hline Psychiatric disorder & 0 & $3(1)$ & 0 \\
\hline Renal or urinary disorder & $3(1)$ & 0 & 0 \\
\hline Corticotropin insufficiency & $1(<1)$ & 0 & 0 \\
\hline Metabolic or nutritional disorder & $3(1)$ & 0 & 0 \\
\hline \multicolumn{4}{|l|}{ Decrease in laboratory value } \\
\hline \multicolumn{4}{|l|}{ Hemoglobin } \\
\hline To 8.5 to $\leq 10 \mathrm{~g} / \mathrm{dl}$ & $71(27)$ & $73(28)$ & $20(15)$ \\
\hline To $<8.5 \mathrm{~g} / \mathrm{dl}$ & $28(11)$ & $36(14)$ & $7(5)$ \\
\hline \multicolumn{4}{|l|}{ Neutrophil count } \\
\hline Grade 3 & $54(20)$ & 49 (19) & $18(14)$ \\
\hline Grade 4 & $8(3)$ & $11(4)$ & $6(5)$ \\
\hline
\end{tabular}

* Listed are serious adverse events that occurred in at least two patients in a study group.

$\dagger$ These discontinuations all occurred during the phase of the study in which telaprevir or placebo was being administered. Of the patients who discontinued telaprevir, 22 in the T12PR48 group and 18 in the lead-in T12PR48 group continued treatment with peginterferon plus ribavirin. (Details regarding discontinuations of peginterferon, ribavirin, and all study drugs together are available in Table 3 in the Supplementary Appendix.)

$\lceil$ Included in this category are all related events that were described with a variety of descriptive terms.

tation of our study was that patients were not randomly assigned according to this marker, since it had not been discovered at the time of enrollment. However, consent for genetic testing was collected from a sizable proportion of patients. Since consent for genetic testing requires the deidentification of samples and analysis by an independent group, results for interleukin-28B testing are not part of our study.

In conclusion, the addition of telaprevir to peginterferon alfa-2a plus ribavirin significantly increased the rates of sustained virologic response for patients who are chronically infected with HCV genotype 1 and in whom peginterferon plus ribavirin had failed to achieve viral eradication, including those with a high viral load, severe liver fibrosis, and cirrhosis. The safety profile of telaprevir was consistent with the findings in previous trials.

Supported by Tibotec and Vertex Pharmaceuticals.

Disclosure forms provided by the authors are available with the full text of this article at NEJM.org.

We thank the members of the data and safety monitoring board: chairperson Francesco Negro, University Hospitals, Geneva; Dominique Larrey, Hôpital Saint Eloi, Montpellier, France; and Tim Friede, University Medical Center, Göttingen, Germany; the study coordinators, nurses, and patients who were involved in the study; and Isabelle Lonjon-Domanec and Ryan Woodrow for their assistance in the preparation of the manuscript.

APPENDIX

The authors' affiliations are as follows: Johann Wolfgang Goethe University Medical Center, Frankfurt am Main, Germany (S.Z.); Dipartimento di Medicina Clinica, Alma Mater Studiorum, Università di Bologna, Bologna, Italy (P.A.); Université Paris Descartes, INSERM Unité 1016, and Assistance Publique-Hôpitaux de Paris, Cochin Hospital, Paris (S.P.); Alamo Medical Research, San Antonio, TX (E.L.); Clinica Quiron, Valencia, Spain (M.D.); Department of Gastroenterology, Alfred Hospital, Melbourne, VIC, Australia (S.R.); Emilio Ribas Infectious Diseases Institute, São Paulo (R.F.); Center for Liver Disease, Inova Fairfax Hospital, Falls Church, VA (Z.Y.); Queen Mary University of London, Institute of Cell and Molecular Science, London (G.R.F.); Medical University of Warsaw, Warsaw, Poland (A.H.); Medical University of Vienna, Internal Medicine III, Department of Gastroenterology and Hepatology, Vienna (P.F.); Department of Hepatology, University Hospital Gasthuisberg K.U. Leuven, Leuven, Belgium (F.N.); Swiss Hepato-Pancreato-Biliary Center and Division of Gastroenterology and Hepatology, University Hospital Zurich, Zurich, Switzerland (B.M.); Scripps Clinic and Scripps Research Institute, La Jolla, CA (P.P.); Hospital Municipal de Gastroenterologia Dr. Bonorino Udaondo, Capital Federal, Argentina (R.T.); Liver Unit, Hadassah-Hebrew University Hospital, Ein-Kerem, Jerusalem, Israel (D.S.); Department of Gastroenterology and Hepatology, Leiden University Medical Center, Leiden, the Netherlands (B.H.); Karolinska Institutet, Karolinska University Hospital Huddinge, Stockholm (O.W.); and Tibotec, Beerse, Belgium (R.V.H., S.D.M., G.B., M.B.), and Titusville, NJ (D.L., R.P., G.P.). 
REFERENCES

1. McHutchison JG, Lawitz EJ, Shiffman $\mathrm{ML}$, et al. Peginterferon alfa-2b or alfa-2a with ribavirin for treatment of hepatitis $\mathrm{C}$ infection. N Engl J Med 2009;361:580-93. [Erratum, N Engl J Med 2009;361:1027.] 2. Guidance for industry - chronic hepatitis $\mathrm{C}$ virus infection: developing directacting antiviral agents for treatment. Silver Spring, MD: Food and Drug Administration, September 2010. (http://www.fda.gov/ downloads/Drugs/GuidanceCompliance RegulatoryInformation/Guidances/ UCM225333.pdf.)

3. Lin $K$, Perni $R B$, Kwong $A D$, Lin $C$. VX-950, a novel hepatitis $\mathrm{C}$ virus (HCV) NS3-4A protease inhibitor, exhibits potent antiviral activities in $\mathrm{HCV}$ replicon cells. Antimicrob Agents Chemother 2006; 50:1813-22.

4. McHutchison JG, Manns MP, Muir AJ, et al. Telaprevir for previously treated chronic HCV infection. N Engl J Med 2010;362: 1292-303. [Erratum, N Engl J Med 2010; 362:1647.]

5. Berg T, McHutchison JG, Adda N, et al. SVR with telaprevir, peginterferon alfa$2 \mathrm{a}$ and ribavirin in HCV patients with well-characterized prior null response, partial response, viral breakthrough or relapse after PR: rollover study 107 . Hepatology 2010;52:Suppl 1:S2. abstract.

6. Kieffer TL, Sarrazin C, Miller JS, et al. Telaprevir and pegylated interferon-alpha-2a inhibit wild-type and resistant genotype 1 hepatitis $\mathrm{C}$ virus replication in patients. Hepatology 2007;46:631-9.
7. Schiff E, Poordad F, Jacobson I, et al. Boceprevir (B) combination therapy in null responders (NR): response dependent on interferon responsiveness. J Hepatol 2008;48:Suppl:S46. abstract.

8. Bacon BR, Gordon SC, Lawitz E, et al. Boceprevir for previously treated chronic HCV genotype 1 infection. N Engl J Med 2011;364:1207-17.

9. Poynard T, Colombo M, Bruix J, et al. Peginterferon alfa-2b and ribavirin: effective in patients with hepatitis $\mathrm{C}$ who failed interferon alfa/ribavirin therapy. Gastroenterology 2009;136:1618-28.

10. Shiffman ML, Di Bisceglie AM, Lindsay $\mathrm{KL}$, et al. Peginterferon alfa-2a and ribavirin in patients with chronic hepatitis $\mathrm{C}$ who have failed prior treatment. Gastroenterology 2004;126:1015-23.

11. Kwo PY, Lawitz EJ, McCone J, et al Efficacy of boceprevir, an NS3 protease inhibitor, in combination with peginterferon alfa-2b and ribavirin in treatmentnaive patients with genotype 1 hepatitis $C$ infection (SPRINT-1): an open-label, randomised, multicentre phase 2 trial. Lancet 2010;376:705-16.

12. Sarrazin C, Zeuzem S. Resistance to direct antiviral agents in patients with hepatitis $\mathrm{C}$ virus infection. Gastroenterology 2010;138:447-62.

13. McHutchison JG, Everson GT, Gordon SC, et al. Telaprevir with peginterferon and ribavirin for chronic HCV genotype 1 infection. N Engl J Med 2009;360:1827-38. [Erratum, N Engl J Med 2009;361:1516.
14. Hézode C, Forestier N, Dusheiko G, et al. Telaprevir and peginterferon with or without ribavirin for chronic HCV infection. N Engl J Med 2009;360:1839-50.

15. Jacobson IM, McHutchison JG, Dusheiko G, et al. Telaprevir for previously untreated chronic hepatitis $\mathrm{C}$ virus infection. N Engl J Med 2011;364:2405-16.

16. Sherman KE, Flamm SL, Afdhal NH, et al. Telaprevir in combination with peginterferon alfa-2a and ribavirin for 24 or 48 weeks in treatment-naïve genotype 1 HCV patients who achieved an extended rapid viral response: final results of phase 3 ILLUMINATE study. Hepatology 2010; 52:Suppl:400A. abstract.

17. Marcellin P, Forns X, Goeser T, et al. Telaprevir is effective given every 8 or 12 hours with ribavirin and peginterferon alfa-2a or $-2 b$ in patients with chronic hepatitis C. Gastroenterology 2011;140(2): 459.e1-468.e1.

18. Thompson AJ, Muir AJ, Sulkowski MS, et al. Interleukin-28B polymorphism improves viral kinetics and is the strongest pretreatment predictor of sustained virologic response in genotype 1 hepatitis Cvirus. Gastroenterology 2010;139(1):120. e18-129.e18.

19. Ge D, Fellay J, Thompson AJ, et al. Genetic variation in IL28B predicts hepatitis $\mathrm{C}$ treatment-induced viral clearance. Nature 2009;461:399-401.

Copyright (c) 2011 Massachusetts Medical Society. 